\title{
ESTRATÉGIA DE ENSINO COM FOCO NA LINGUAGEM VISUAL EM CONTEXTO MULTICULTURAL
}

\author{
Gabriela Barbosa Souza \\ Mestre em Educação \\ Professora da Faculdade \\ Eugênio Gomes, Ipirá/BA \\ gabibarbosa_fsa@hotmail.com \\ Lílian Miranda Bastos \\ Pacheco \\ Doutora \\ Professora do Departamento \\ de Educação, UEFS \\ lilianmbp01@gmail.com
}

\section{RESUMO:}

Este estudo objetiva evidenciar a importância do uso do desenho no desenvolvimento do processo de escrita de alunos do 5 o ano, em uma escola básica indígena. Foi proposta uma estratégia pedagógica utilizando-se uma sequência didática com o gênero textual conto. Os alunos, interagindo em grupos, se dedicaram à escrita da produção inicial e final do gênero textual. Depois da produção inicial, foram realizadas mediações pedagógicas com foco no uso do desenho e da linguagem oral, promovendo a representação gráfica dos episódios da narrativa. Foram analisados a estrutura da narrativa e o registro de aspectos da cultura local. Ao se tratar da estrutura textual, percebeu-se que as intervenções pedagógicas, realizadas com foco no uso das linguagens oral, visual e escrita, facilitaram a ampliação das competências dos alunos, no que se refere à organização dos elementos constituintes do conto. Quanto ao registro da cultura indígena, a maioria dos grupos conseguiu construir a segunda versão das narrativas com mais detalhes culturais, em comparação à primeira versão. Notase que, a partir do trabalho com o desenhar e com o diálogo, os alunos foram estimulados a produzir um texto mais coeso, assim como mais rico em aspectos da cultura local.

Palavras-chave: Estratégia de ensino, Sequência Didática, Gênero textual, Desenho, Ensino Multicultural. 


\section{INTRODUÇÃO}

A importância do trabalho pedagógico com gêneros textuais vem sendo evidenciada em documentos legais (BRASIL, 1998) e por estudiosos (MARCUSCHI, 2002; FERREIRA e DIAS, 2005; MACHADO e LOUSADA, 2010) que propõem delineamentos metodológicos para desenvolvimento da produção textual por alunos e professores.

0 grupo de Pesquisa em Desenvolvimento Humano e Processos Educativos (DEHPE) da Universidade Estadual de Feira de Santana/BA tem desenvolvido o projeto "Narrativas e Representações", com o objetivo de problematizar o ensino/aprendizagem e a produção de material paradidático com comunidade multicultural. Prevê situações de trocas, ensino, pesquisa e extensão, entre a universidade e a escola básica indígena. 0 objetivo principal é estabelecer diálogos entre a cultura local/universal, em espaços de educação escolar, entre diferentes culturas, principalmente no que se refere às narrativas culturais.

Este estudo é resultante do referido projeto de pesquisa/ensino/extensão realizado em uma comunidade multicultural, e objetiva evidenciar a importância do uso do desenho no desenvolvimento do processo de escrita de alunos em uma escola básica indígena.

\section{ESTRATÉGIA DE ENSINO COM GÊNEROS TEXTUAIS}

As diretrizes contidas no Parâmetros Curriculares Nacionais de Língua Portuguesa (BRASIL, 1998) recomendam a utilização de atividades com diferentes gêneros textuais como um facilitador do ensino de produção e leitura de textos.

Gancho (2007) conceitua gênero como um tipo de texto literário, definido de acordo com a estrutura, o estilo e a recepção junto ao público leitor e/ou ouvinte. Machado e Lousada (2010) destacam que os gêneros textuais podem se constituir em instrumentos para os alunos e para os professores, uma vez que eles podem influenciar profundamente na construção do saber e nos processos de conceitualização do próprio professor (sobre produção e leitura).

Marcuschi (2002) aborda os gêneros textuais como uma estratégia profundamente vinculada à vida cultural e social, uma vez que oportuniza o lidar com a língua em seus mais diversos usos autênticos no dia-a-dia. Por sua vez, Oliveira (2009) defende que o ensino seja com os gêneros textuais e não sobre eles, o que significa considerá-los como elemento organizador da ação de ensinagem, exigindo assim que o currículo seja organizado como algo flexível, dinâmico e voltado para a realidade local.

Ferreira e Dias (2005) discutem os conceitos de texto, contexto e gênero textual, enfatizando-se a ideia de que o sentido se constitui na relação dialética entre autor \texto\leitor\contexto. Nascimento (2010) chama a atenção dos professores do Ensino Fundamental para que o ensino com textos 
aconteça com mais frequência e que esse uso possa articular-se coerentemente dentro de uma proposta interdisciplinar atendendo às indicações dos Parâmetros Curriculares Nacionais de Língua Portuguesa (opus cite), principalmente no que se refere à diversidade textual.

Buscou-se trabalhar com os gêneros textuais narrativos, ao considerar que estes podem possibilitar a relação dos conhecimentos formais da língua relacionados ao conhecimento cultural dos alunos. Estudos destacam a importância do trabalho com narrativas (VIEIRA e SPERB, 1998, 2007), não só pela oportunidade de lidar com o imaginário, mas também por desenvolver habilidades metalinguísticas e por dar oportunidade ao sujeito, falante da cultura, para simbolizá-la, deixar registro e refletir sobre esta ação. 0 ato de registrar gera aprendizagem e memória.

Cunha (1998) destaca que o uso didático da memória/ história de vida tem se revelado como interessante instrumento de formação. Uma vez que permite a concretização dos pressupostos teóricos de um processo ensinoaprendizagem que tenha o sujeito e a cultura como ponto básico de referência.

Segundo Marcuschi (2002, p.151) o estudo dos gêneros textuais é hoje uma fértil área interdisciplinar com atenção especial para a linguagem em seu funcionamento de forma integrada com as atividades culturais e sociais. Nesta perspectiva, é notável a importância de trabalhos linguísticos voltados para comunidades multiculturais, possibilitando o conhecimento dos aspectos formais da língua e o registro dos saberes das diversas culturas. Esse registro pode ser potencializado através do uso interativo entre as linguagens visual e escrita. A seguir, discute-se a importância do desenho para o processo de aprendizagem.

\section{A IMPORTÂNCIA DO DESENHO PARA O PROCESSO DE APRENDIZAGEM}

Autores (AIRES e BASTOS, 2011; SANTOS, 2014; CUNHA, 2015; SOUZA, SUZART e PACHECO, 2015) têm discutido sobre a importância do desenho para o processo de ensino-aprendizagem.

Cunha (2015) considera que o trabalho pedagógico com as linguagens visuais pode dar a oportunidade a uma melhor apropriação do conhecimento em situações de ensino/aprendizagem. Isso pode ocorrer à medida em que se crie situações ou oportunidades de ampliação de repertórios visuais, questionamento dos significados das imagens, compartilhamento das concepções visuais e produção de autoimagens por meio da fotografia, desenhos, pinturas, entre outras modalidades expressivas no contexto escolar. A autora ressalta que temos ainda pouca experiência em utilizar as imagens como linguagem capaz de socializar ideias, enfatizando que isso se deve ao equivocado:

(...) entendimento de que a forma mais adequada para expressar pensamentos e argumentações teóricas é a palavra, escrita ou falada. Nota-se que há uma hierarquização entre as duas linguagens: a escrita porta o "conhecimento, o saber e a verdade", e as imagens, muitas vezes, servem para expressar sentimentos e, 
quando muito, como "prova" de um acontecimento, um registro que "ilustra", “comprova” e enaltece a veracidade do que é escrito.

Aires e Bastos (2011) buscaram evidenciar as representações sociais sobre meio ambiente de alunos da Educação Básica de Palmas (T0) através da técnica mapas mentais. De acordo com os autores, através dos mapas mentais, foi possível "desvelar as dimensões do vivido, do percebido e do concebido na representação do Meio Ambiente dos estudantes, onde está inserida tanto a dimensão significativa quanto a dimensão interativa" (AIRES e BASTOS, 2011, p.363). Através do desenho, os estudantes conseguiram representar suas experiências individuais e coletivas em torno da temática meio ambiente.

Santos (2014) objetivou em seu estudo tecer algumas reflexões acerca da produção acadêmica sobre o desenho na área da Educação Infantil, entre os anos de 1990 a 2003, em periódicos classificados pela QUALI-CAPES como de excelência. Levantou questionamentos sobre como o professor é/ou não sensibilizado em sua formação para trabalhar com as representações gráficas infantis. A autora considera que no período investigado “(...) o número de publicações sobre a referida temática foi bastante tímido em relação a outros temas" (SANTOS, 2014, p. 66)

Para Santos (2014, p. 66) as discussões sobre o desenho infantil é relevante, visto que "o desenho é considerado um recurso gráfico que revela a necessidade inerente ao homem, desde criança bem pequena, de se expressar e comunicar". Através do desenho, a criança manifesta seus sentimentos e experiências vivenciadas em seu cotidiano. No que se refere à formação de professores para um olhar diferenciado quanto ao desenho infantil, Santos (2014, p.83) afirma que:

(...) Defendemos um professor que seja sensível e atento as múltiplas linguagens, sobretudo, a lúdica e a expressiva, já que estamos falando de crianças. Neste contexto, o desenho que tão pouca atenção vem recebendo dos pesquisadores precisa ser encarado e visto com mais seriedade, pois, através dele, podemos acompanhar o desenvolvimento cognitivo, social e emocional das crianças. (SANTOS, 2014, p. 83)

Em um estudo realizado por Souza, Suzart e Pacheco (2015), foi verificado que já existe uma quantidade considerável de estudos sobre imagens divulgados na base de dados digital Scielo.br, mas quando se investiga sobre as imagens visuais e aprendizagem, um número reduzido de pesquisas é encontrado. Em 2015, na referida base de dados foram encontrados seis artigos, destes três se referem à tecnologia assistiva e/ou à Educação Inclusiva (NERY, BATISTA, 2004; KASTRUP, SAMPAIO, ALMEIDA, CARIJÓ, 2009; BIDARRA, BROSCARIOLI, PIRES, 2011), dois estudos se referem ao contexto escolar no que se refere ao uso de narrativas e desenhos no ensino de temas geocientíficos (COMPIANI, 2013) e o desenvolvimento de habilidades para a compreensão e geração de textos visuais (OLIVEIRA, 2007). Outro artigo (CESARINO, 2013) trata do contexto educativo cultural indígena do povo Marubos, da Amazônia. 
Oliveira (2007, p. 195) destaca a importância da inclusão do letramento visual no currículo escolar e ressalta a relevância de que os alunos sejam:

(...) conscientizados para identificar o papel que a imagem desempenha em contextos variados, questionar a intenção do fotógrafo e como tal intenção se realiza por meio do uso de cores, enquadramento, posições, ângulos, e o que ele pretendeu comunicar com isso tudo, bem como a intenção que circunstância a veiculação de tal imagem.

O letramento visual deve ser considerado nos currículos escolares, visto que pode possibilitar a interdisciplinaridade, aspecto evidenciado por Compiani (2013). Além disso, destaca-se a relevância do trabalho com imagens de forma crítica e analítica, o qual poderá viabilizar o desenvolvimento de um pensamento mais histórico-argumentativo. Através do desenho, pode acontecer o processo de registro e expressão de vivências socioculturais.

\section{CAMINHO METODOLÓGICO}

Este trabalho foi desenvolvido em uma turma do 5o ano do Ensino Fundamental I, de um colégio estadual indígena, localizado no município de Pau-Brasil, Bahia, a qual era composta por 17 alunos, sendo 6 do sexo masculino e 11 do sexo feminino, com a faixa etária entre 9 e 11 anos. A escolha dessa turma deveu-se ao fato de encontrarem-se no $5^{\circ}$ ano, último ano do Ensino Fundamental I, e consequentemente ter a necessidade de um trabalho diferenciado no que se refere ao uso das linguagens.

0 delineamento metodológico da presente pesquisa desenvolveu-se através de uma estratégia de ensino, que utilizou o instrumento pedagógico Sequência Didática. De acordo com Dolz, Noverraz e Schneuwly (2004, p. 97) Sequência Didática configura-se como "(...) um conjunto de atividades escolares organizadas, de maneira sistemática, em torno de um gênero textual oral e escrito". Para os autores, tal recurso tem como finalidade "ajudar o aluno a dominar melhor um gênero de texto, permitindo-lhe, assim, escrever ou falar de uma maneira mais adequada numa dada situação de comunicação" (DOLZ, NOVERRAZ e SCHNEUWLY, 2004, p.97).

A turma foi dividida em cinco grupos, para a escrita de duas versões do gênero textual conto, sendo uma produção inicial e a outra produção final. 0 trabalho foi desenvolvido em grupos por considerar que a interação e conversação podem levar as crianças a trocarem informações e a testá-las durante a construção do texto, assim como é destacado no estudo de Leal e Luz (2001).

Inicialmente, os alunos foram despertados para a escrita de contos referentes à sua própria cultura, mediante a leitura do conto "O amigo do Rei" de Ruth Rocha (2009). O referido conto foi escolhido por se tratar de uma narrativa que aborda a interação entre duas culturas, a dita branca e a afrodescendente. No intuito de servir de contraponto para despertar os alunos para a escrita de contos referentes à sua própria cultura. 
A partir das produções iniciais dos contos e da dinâmica da turma, foram desenvolvidas intervenções informativas, explicativas, buscando possibilitar a compreensão da estrutura textual do conto. Além da solicitação do desenho, promovendo a ilustração das narrativas e a oralidade dos alunos, a fim de que os próprios discentes apresentassem oralmente a sua interpretação dos contos. Objetivamos valorizar as narrativas orais e visuais que se fazem presentes na cultura indígena.

Considera-se que o desenho pode ter características narrativas. Os elementos que o compõem se integram formando um arranjo espacial, um cenário, muitas vezes, representando uma ação através da função simbólica (PIAGET e INHELDER, 1994; PILLAR, 1996).

Posteriormente, os alunos reescreveram seus contos, utilizando como base os desenhos produzidos para registrar cada parte de suas narrativas. Os dados foram analisados através de um roteiro baseado no estudo de Gancho (2007), o qual traz a discussão de como analisar narrativas, levando em consideração os aspectos estruturais de uma narrativa e se nesta narrativa aparece registros culturais. Este estudo objetiva evidenciar a importância do uso do desenho no desenvolvimento do processo de escrita de alunos de uma escola básica indígena.

\section{ANALISANDO OS DADOS}

As produções textuais dos alunos foram analisadas no que se refere à estrutura textual e ao registro da cultura indígena. Como já foi mencionado anteriormente, a turma foi dividida em cinco grupos denominados grupo A, B, C, D, E. Os grupos permaneceram com os mesmos componentes nas duas produções, de forma a permitir a realização de uma análise comparativa.

A análise das produções dos alunos foi baseada nos aspectos constituintes do conto, destacados no estudo de Gancho (2007). Apresentamse, a seguir, os aspectos e seus respectivos conceitos elucidados pela referida autora:

Enredo - conjunto dos fatos de uma história. Gancho (2007) subdivide o enredo nas seguintes partes:

- Exposição - partes do enredo, que consiste no início da história, em que são apresentados seus elementos introdutórios. desenvolvimento.

- Complicação - parte do enredo que corresponde a seu

- Clímax - momento de maior tensão da história.

- Desfecho - parte da narrativa que consiste no final da história.

Espaço - o lugar onde se passa a história.

Tempo - época em que se passa a história.

Personagem - ator principal da história e que, portanto, só existe como tal se participa efetivamente do enredo, isto é, se age e/ou fala. 
Narrador - elemento estruturador da história.

Além dos cinco elementos destacados acima, Gancho (2007) destaca a importância de considerar o assunto na análise de narrativas, que neste caso será o registro da cultura indígena.

Assunto - é a maneira como o tema é desenvolvido concretamente no texto.

Nem sempre todos estes aspectos estão explicitamente presentes no conto. A partir dos referidos aspectos constituintes da narrativa, realizou-se as análises dos dados desta pesquisa. Neste estudo, apresenta-se as narrativas escritas e representadas em desenho do grupo E, além de suas respectivas considerações.

\subsection{Produção Inicial}

Figura 1: Produção Inicial do Grupo E .

A anca caliella

A anla labioda ro uma india guando lla dia, ila sifingia di daunte enaite lla Viraria a enla; 1 anaite la raia para lialer sanque de animais, um. serto dia saiu de casa iai umor hamuns Viu la raindo de cara fai quando eles purlutiram que ela estaría inganando les, os hamens filaram Viqiando la, ai a onka sifigio de marta li quando Ila pai interrada, ai les faram no simiturio movaminte la tíma Virado anca dentro do caixaro, ai la tima impurrado a tampa do caixiõo i tima into para as matas. firm

O grupo E faz uma produção recontando a história da Onça Cabocla. Inicialmente, expõe sua narrativa na $3^{\circ}$ pessoa do singular e caracteriza a personagem principal "a onça cabocla” como uma índia que se fingia de doente. 0 conflito da história acontece mediante a descoberta da onça pelos homens e seu clímax quando os homens vão ao cemitério e descobre que a tampa do caixão tinha sido empurrada. 0 desfecho da narrativa está na informação de que a onça cabocla foi para as matas. 0 tempo da narrativa está na alternância entre o dia e a noite. 
Pacheco (2017, p.99) afirma que:

$\mathrm{Na}$ estrutura das narrativas encontramos um princípio ético organizador do ego. Nesta assim como na vida o tempo aparece como responsável pela ordem social e vai sendo percebido pelo humano a partir da repetição das vivências, dos hábitos, costumes e crenças.

O ser sobrenatural, ou melhor, na cosmovisão indígena o ser da natureza, mais sábio que o ser humano, tem a função de guia, de protetor da vida, da cultura, dos modos e costumes da comunidade. Vive entre eles, observando e se camuflando, uma presença atemporal e onisciente. Considerase que os personagens por nós chamados de "sobrenaturais", na cosmovisão dos povos indígenas não o são. Não compõe uma ficção, mas participa do mundo vivido por cada um de nós.

Souza (2016) coletou contos orais, em um total de 96 contos, das diferentes etnias que compõe o povo Pataxó Hãhãhãi. Com base na classificação de Travaglia (2007) as narrativas foram categorizadas em dois tipos: contos históricos e fantásticos. Os contos de cunho histórico trazem em seu conteúdo relatos de lutas e retomadas do território da Aldeia Indígena Caramuru Paraguaçu, além de acontecimentos cotidianos. Já os contos de cunho fantástico trazem elementos sobrenaturais e refletem o imaginário deste povo indígena. De acordo com Souza (2016, p. 118):

\begin{abstract}
Os contos fantásticos do povo Pataxó Hãhãhãi, a partir da abordagem de fenômenos sobrenaturais, dão vasão a fenômenos e vivências do encantamento e de conflitos antagônicos da psicologia humana, ao mesmo tempo local e universal. Faz-se presente nos contos do povo Pataxó Hãhãhãi, a menção a sentimentos humanos, como o desejo e a sedução, mediados pelo encantamento realizado por um ser fantástico.
\end{abstract}

Em relação ao registro da cultura indígena, percebe-se a relevância da escrita dessa narrativa, uma vez que se trata, segundo a professora da turma, de um conto em que os anciões narram para as gerações mais novas da comunidade. Nesse contexto, Bergamaschi e Medeiros (2010) destacam a relevância do registro das histórias contadas pelos anciões, visto que estas estão sempre correndo risco de extinção junto com a geração que detém o conhecimento de tais narrativas. 0 homem da cidade aprende pelos livros, enciclopédias, hoje em dia pelos meios de comunicação virtuais. Os indígenas já têm acesso a estas tecnologias, mas perpetuam sua cosmovisão através de mitos, lendas e contos, narrativas através das quais os modos e costumes da comunidade são transmitidos de forma contextualizada.

\title{
5.2. Representação Visual da Narrativa
}

Após a produção inicial, os educandos foram orientados a representarem os episódios de sua narrativa em desenhos. 0 grupo E representou cada ação através de seis desenhos que serão apresentados a seguir: 
Figura 2: Desenho do Grupo E

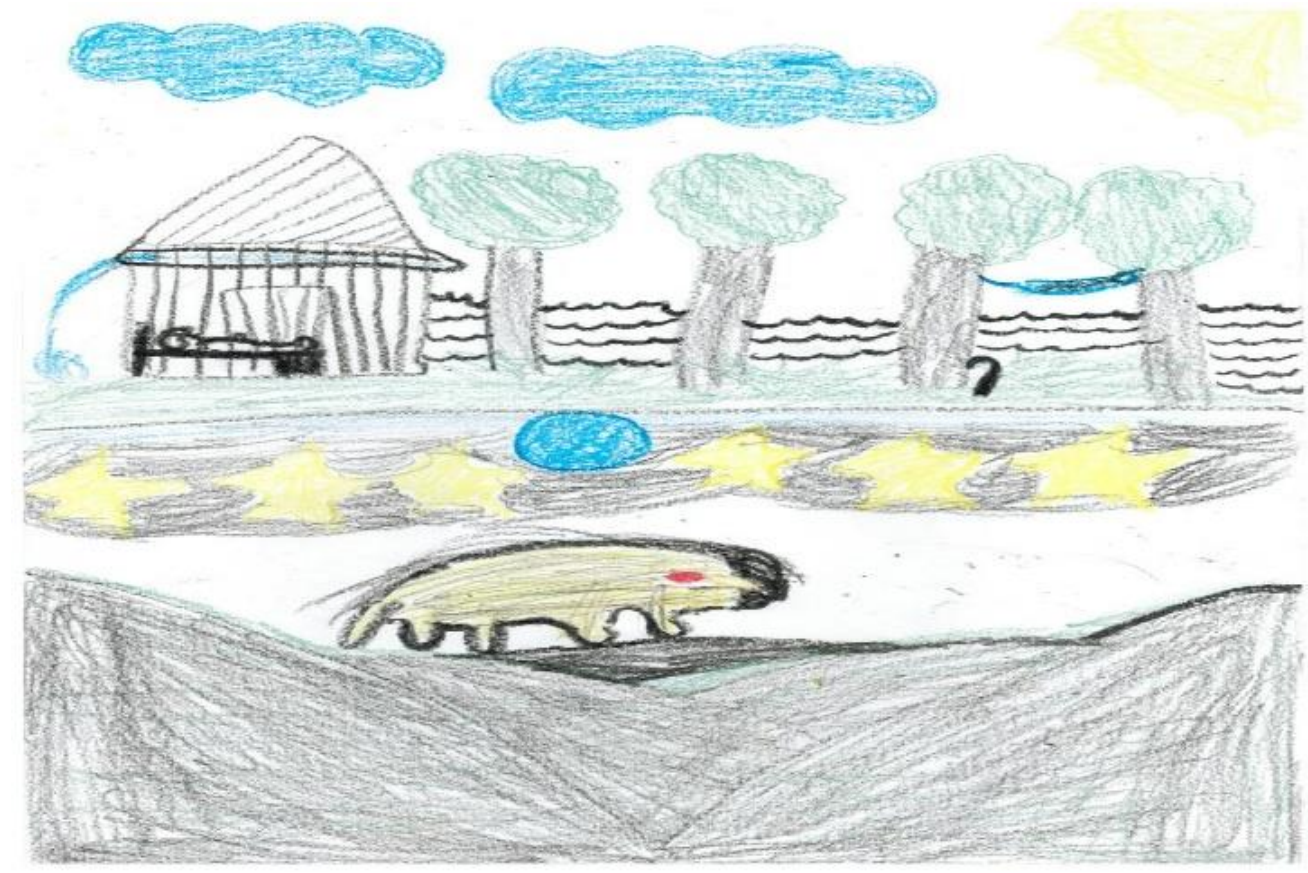

Figura 3: Desenho 2 do Grupo E
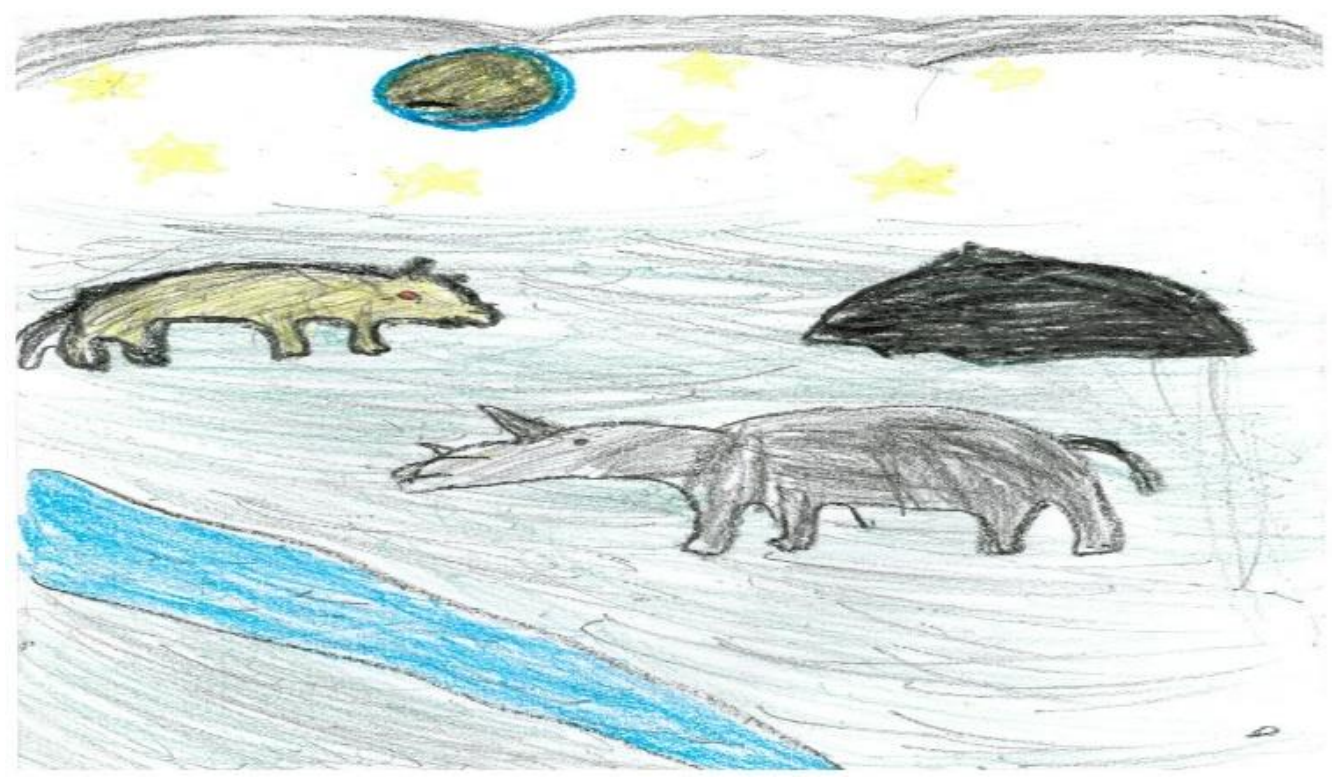
Figura 4: Desenho 3 do Grupo E

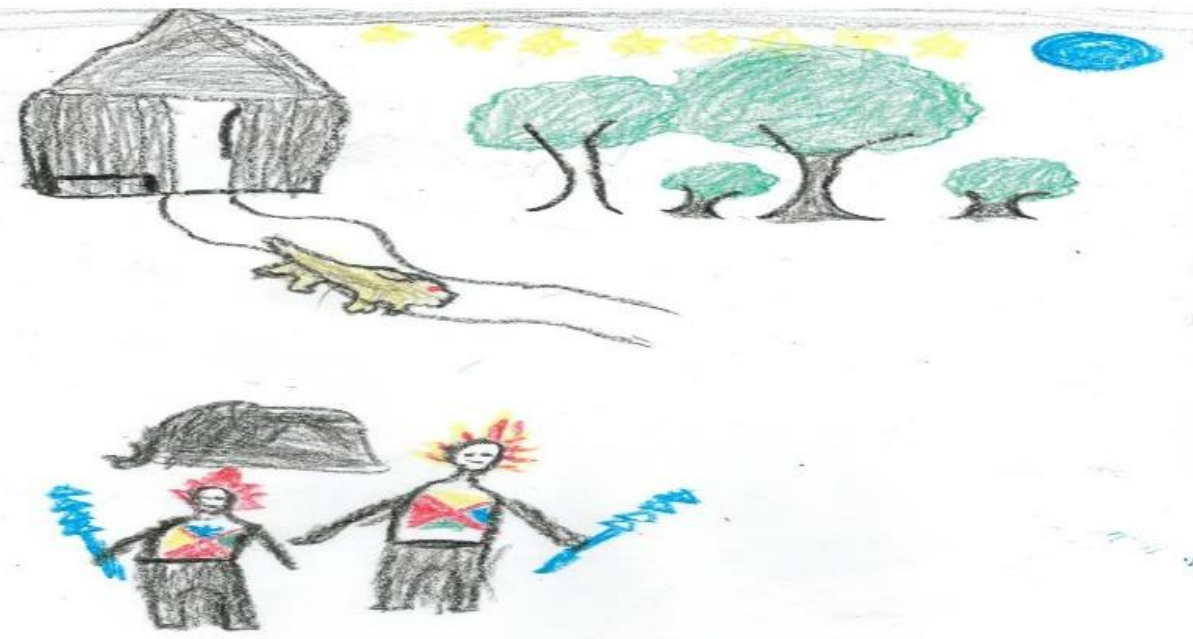

Figura 5: Desenho 4 do Grupo E

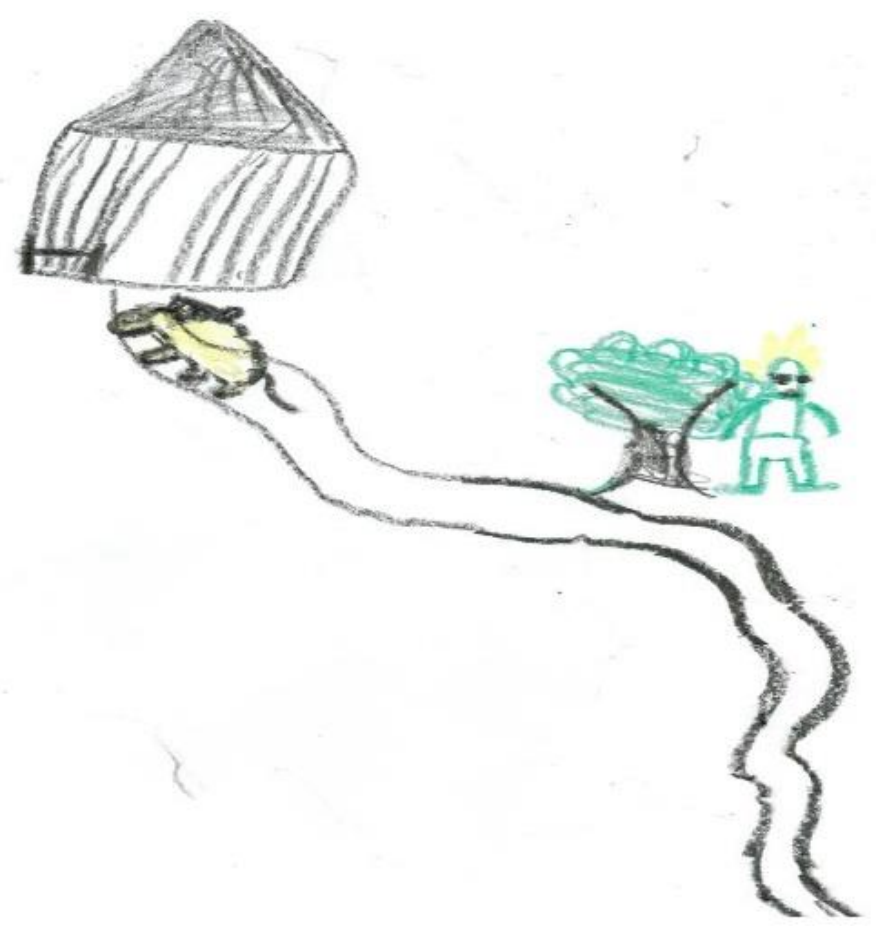


Figura 6: Desenho 5 do Grupo E
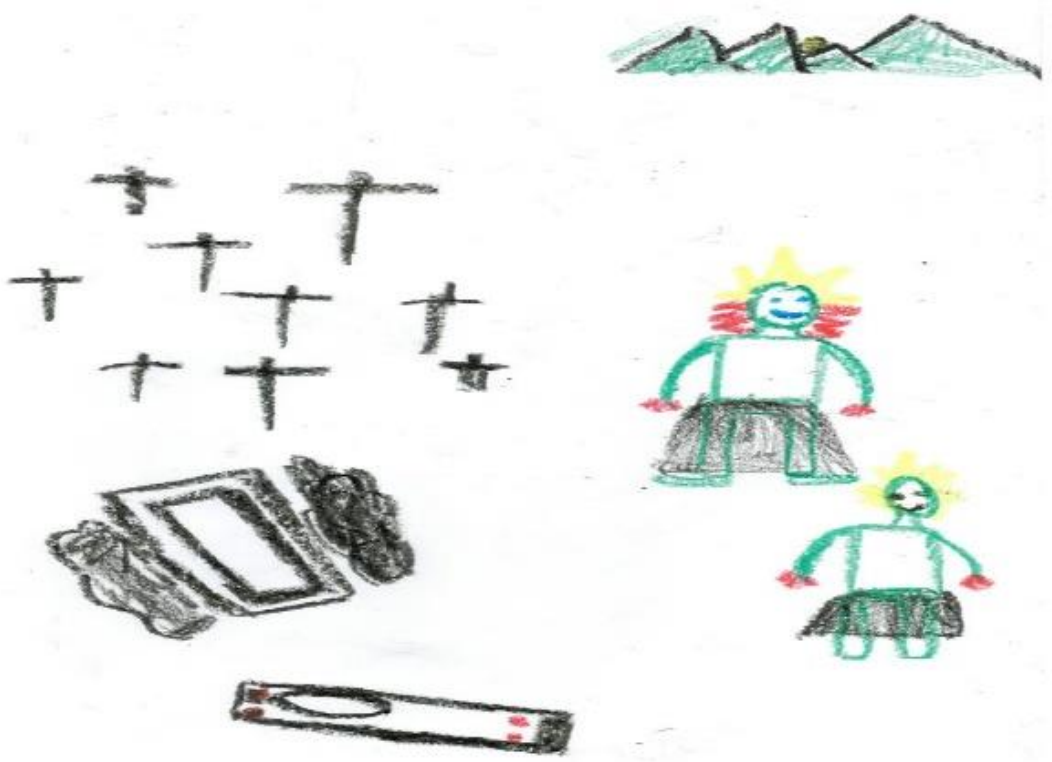

Figura 7: Desenho 6 do Grupo E

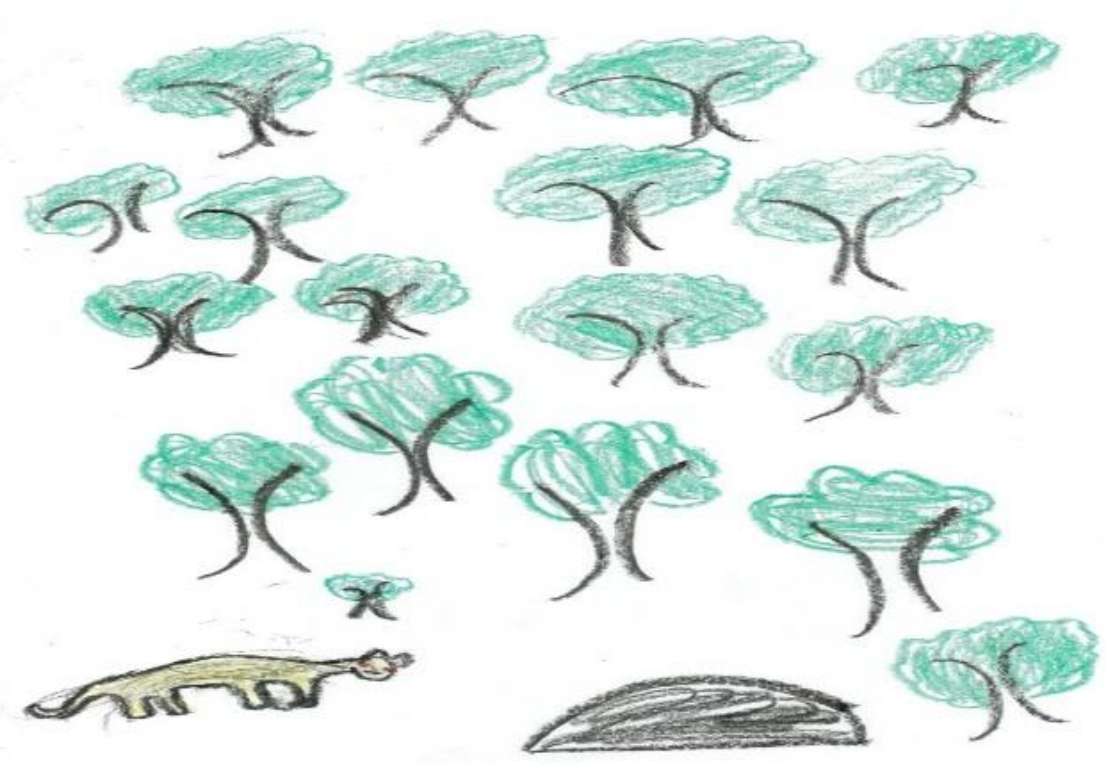

Através do desenho, os alunos representaram ações sequenciais dos personagens da narrativa. É possível notar a representação de aspectos do contexto sociocultural dos educandos indígenas. 0 contato com os animais e a natureza fez-se presente durante toda a narrativa, a partir do meio ambiente representado através das árvores, caminhos, relevo e céu. Munduruku (2009) enfatiza a importância da relação homem-natureza em contextos indígenas e destaca como este valor cultural é transmitido para as crianças. Segundo esse autor: 
Todo o aprendizado de respeito à natureza é transmitido desde o nascimento. A criança vai sendo introduzida no convívio social ao longo dos momentos marcantes do seu processo de crescimento. Até mesmo no ato de ouvir uma história narrada por um velho da aldeia, a criança está aprendendo como deve ser o seu relacionamento com a natureza e que, em tempos imemoriais, eram os animais, as plantas, os peixes, as árvores e as aves que mandavam no mundo e até no homem. (MUNDURUKU, 2009, p. 29)

Aparece também a representação de indígenas com vestimentas e ferramentas da cultura local, constando a presença do cocar com penas coloridas e do tipo de moradia presente na comunidade. Por outro lado, são representados símbolos que são presentes também na sociedade não-índia, como por exemplo, a cruz e o caixão, presentes na Figura 6 para representar o sentimento perante a morte.

Considera-se que as narrativas podem se constituir como uma forma de manifestação de conteúdos inconscientes, visto trazerem, em seu conteúdo, formas de lidar com o inesperado, com o medo, a morte, a angústia, a sedução, o instinto e a ansiedade, destinando aos seres sobrenaturais, muitas vezes, inomináveis e invisíveis, a responsabilidade por seus sentimentos inconscientes reprimidos em seu contexto social.

\subsection{Produção Final}

Figura 8: Produção final do Grupo E

\begin{tabular}{|c|}
\hline A omea caloela e as lofadares \\
\hline 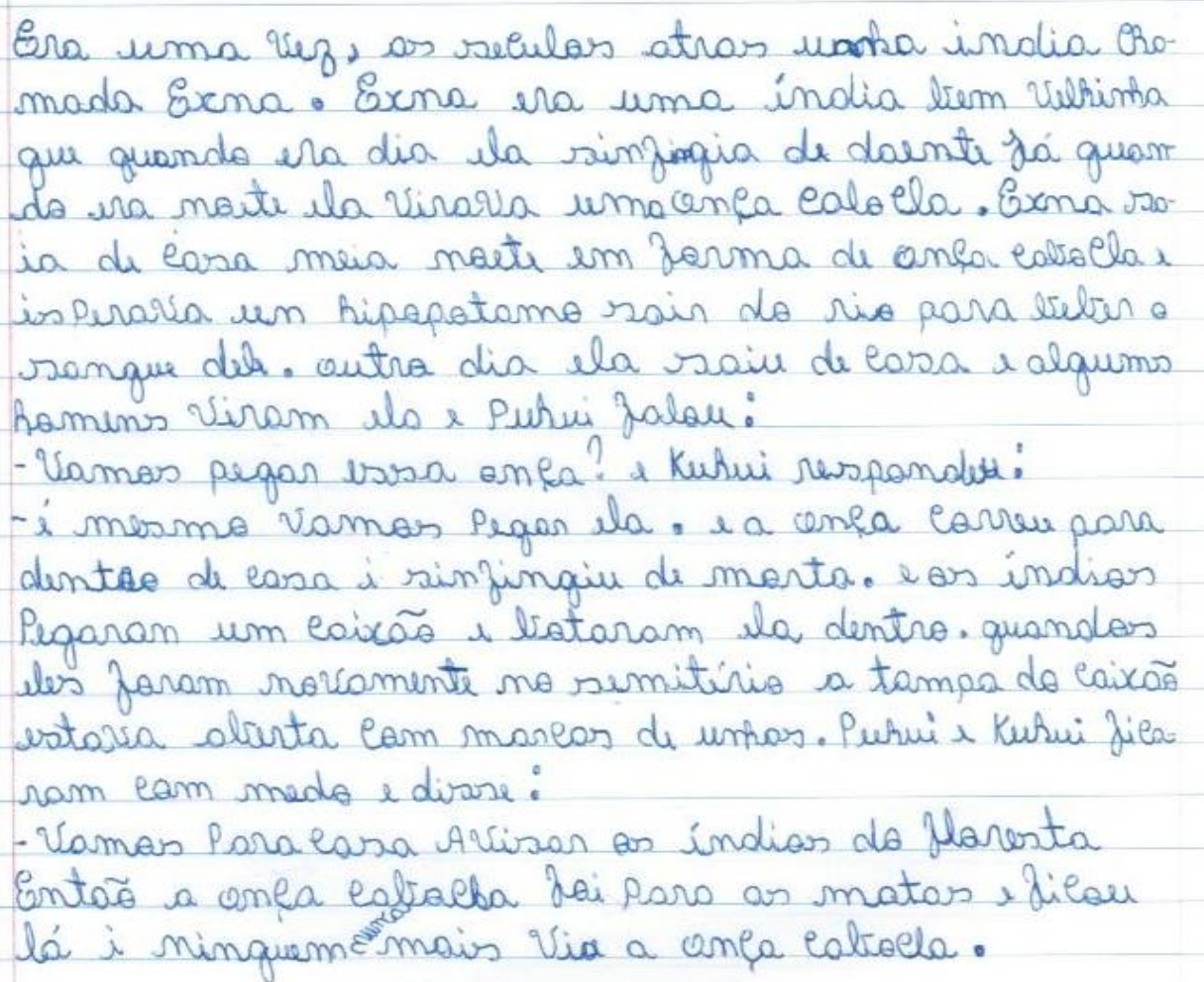 \\
\hline
\end{tabular}


Na segunda produção, o grupo E desenvolveu a exposição de seu conto na 3 o pessoa do singular, inseriu a expressão temporal "há séculos atrás", estar bem velhinha, além da alternância dia/noite a qual já havia sido mencionada. Também nomeou o personagem e protagonista de sua narrativa "Exna", a chamada onça cabocla, "Puhui" e "Kuhui, índios da floresta, relatando mais detalhes, dando nomes aos personagens. Estes aspectos fizeram a narrativa mais completa e detalhada, tal como na caracterização da onça e a introdução dos hábitos cotidianos da personagem.

No que se refere ao registro da cultura indígena, percebe-se a relevância da realização desta produção, uma vez que permitiu ao grupo a ampliação da história a partir do que eles escutam dos anciões. Considera-se assim o papel dos destes enquanto guardião de memória e responsável pela transmissão da cosmologia cultural da comunidade indígena. De acordo com Munduruku (2009, p. 70):

\begin{abstract}
0 conhecimento, na sociedade indígena, é dominado pelos mais velhos. Mesmo que uma pessoa saiba todas as coisas sobre seu povo, sobre sua tradição, se houver alguém mais velho presente naquele espaço, é de direito que ele responda o que foi perguntado. [...] Por uma questão de respeito àquela pessoa que já tem uma caminhada mais longa, faculta-se lhe o direito de aconselhar, dirigir, coordenar, opinar e curar as pessoas. A ele é dado o direito de ser mestre e de exercer a sua sabedoria.
\end{abstract}

Aos anciãos é destinado o papel de experiente e conhecedor das narrativas indígenas, de acordo com Munduruku (2009). Souza (2016, p. 118), ao analisar os contos fantásticos do povo indígena Pataxó Hãhãhãi, considera que a narração dos contos na realidade local tem a função sociocultural de transmissão de ensinamentos e valores culturais singulares". Dentre estes valores, destacam-se "a importância da preservação da natureza, o respeito aos anciãos enquanto guardiões de memória, o perigo da vida na floresta e normas de conduta necessárias ao trabalho coletivo desta comunidade indígena" (SOUZA, 2016, p. 118). Considera-se a importância do trabalho pedagógico organizado através das narrativas orais, escritas e visuais em espaços multiculturais, possibilitando o conhecimento de valores culturais e a estrutura formal da língua.

\title{
6. CONCLUSÃO
}

Ao se tratar da estrutura textual, percebeu-se que as intervenções pedagógicas realizadas com foco nas linguagens oral, visual e escrita facilitaram a ampliação das competências dos alunos no que se refere à organização dos elementos constituintes do conto. Quanto ao registro da cultura indígena, a maioria dos grupos, como foi o caso do grupo E, conseguiu construir a segunda versão das narrativas com mais detalhes culturais comparando à primeira versão. Nesse contexto, nota-se que a partir do trabalho com o desenho e a conversa em grupo, conseguiu-se estimular os alunos a produzirem um texto mais coeso e com aspectos da cultura local. 
Considera-se que este estudo resultante de um projeto de pesquisa/ensino/extensão em contexto multicultural, pode ter como consequência a formação continuada de professores, compartilhando com eles ferramentas que podem facilitar o desempenho escolar dos alunos, tanto no que se refere às habilidades básicas de conhecimento da leitura, da escrita e do desenho, como às contradições entre a cultura universal e local.

Conclui-se a importância do planejamento de estratégias de ensino que contemplem as diversas linguagens e o diálogo entre os pares, possibilitando aos educandos a produção de conhecimento e expressão de suas vivências socioculturais. Ressalta-se a necessidade de ações pedagógicas de leitura/escrita/desenho contextualizada com a vida da comunidade.

\section{REFERÊNCIAS BIBLIOGRÁFICAS}

AIRES, Berenice Feitosa da Costa; BASTOS, Rogério Pereira. Representações sobre o meio ambiente de alunos da Educação Básica de Palmas (TO). Revista Ciência e Educação, v. 17, nº. 2, p. 353-364, 2011.

BERGAMASCHI, Maria Aparecida; MEDEIROS, Juliana Schneider. História, memória e tradição na educação escolar indígena. Revista Brasileira de História. São Paulo, V. 30, nº 60, p.55-75, 2010.

BIDARRA, Jorge; BOSCARIOLI, Clodis; PERES, Sarajane. Software xLupa: um ampliador de tela para auxílio na educação de alunos com baixa visão. Revista Brasileira de Educação Especial, vol. 17, nº 1, p. 151-172, 2011.

BRASIL. Parâmetros Curriculares Nacionais. Ensino Fundamental: Língua Portuguesa. Brasília. MECISEF. 1998.

CESARINO, Pedro. Cartografias do cosmos: conhecimento, iconografia e artes verbais entre os Marubo. Revista Mana, vol. 19, nº 3, p. 437-471, 2013.

COMPIANI, Maurício. Narrativas e desenhos (imagens) no ensino fundamental com temas geocientíficos. Revista Ciência Educação, vol. 19, n 3, p.715-737, 2013.

CUNHA, M. I. Conta-me agora! As narrativas como alternativas pedagógicas na pesquisa e no ensino. Faculdade de Educação, USP. São Paulo, 1998.

CUNHA, Susana Rangel Vieira da. Qual o lugar dos materiais visuais na pesquisa em Educação? Educação em Revista. Belo Horizonte, v. 31, nº 01, p. 69-91, Janeiro/Março, 2015.

DOLZ, J.; SCHNEUWLY, B. Gêneros e Progressão em Expressão Oral e Escrita: Elementos para reflexões sobre uma experiência Suíça (Francófona). In: DOLZ, J; SCHNEUWLY, B; e colaboradores. Gêneros Orais e Escritos na Escola. Tradução e Organização de Roxane Rojo e Glaís Sales Cordeiro. Campinas/ SP: Mercadode Letras, 2004. 
FERREIRA, Sandra Patrícia Ataíde; DIAS, Maria da Graça B. B. Leitor e leituras: Considerações sobre Gêneros Textuais e Construção de sentidos. Revista Psicol. Reflex. Crit. (online) - vol.18 n.3 pp. 323-329, 2005.

GANCHO, Cândida Vilares. Como analisar narrativas. Série Princípios $-7^{\circ}$ Edição, 2007.

KASTRUP, Virgínia; SAMPAIO, Eliana; ALMEIDA, Maria Clara de; CARIJO, Felipe Herkenhoff. O aprendizado da utilização da utilização sensorial visuo-tátil por pessoas com deficiência visual: primeiras experiências e estratégias metodológicas. Revista Psicologia Social, vol. 21, nº 2, p. 256-265, 2009.

KRESS, G.; VAN LEEUWEN, T. Multimodal Discourse: The modes and media of contemporary communication. London: Arnold, 2001.

LEAL, Telma Ferraz; LUZ, Patrícia Santos. Produção de textos narrativos em pares: reflexões sobre o processo de interação. Revista Educação e Pesquisa. São Paulo, v. 27, n.1, p.27-45, jan.ljun, 2001.

MACHADO, Anna Rachel; LOUSADA, Eliane Gouvêa. A apropriação de gêneros textuais pelo professor: em direção ao desenvolvimento pessoal e á evolução do métier. Ling. (dis) curso (impr.) (online)- vol.10 n.3, PP. 619- 633, 2010.

MARCUSCHI, Luiz Antonio. Gêneros textuais: Definição e funcionalidade. In: DIONISIO, Ângela Paiva (org.). Gêneros textuais \& ensino. Editora Lucerna. Rio de Janeiro, 2002.

MUNDURUKU, Daniel. O Banquete dos Deuses: Conversa sobre a origem da cultura brasileira. São Paulo: Global, 2009.

NASCIMENTO, H. A. dos S.. A importância da utilização dos Gêneros textuais nas práticas pedagógicas dos professores de Língua Portuguesa. Pernambuco, 2010.

NERY, Clarisse; BATISTA, Cecília. Imagens visuais como recursos pedagógicos na educação de uma adolescente surda: um estudo de caso. Revista Paidéia, vol. $14, n^{\circ} 29$, p. 287-299, 2004.

OLIVEIRA, Odisséa Boaventura. Reflexões sobre a escrita na formação inicial de professores. Revista Educação (online) n.34, pp. 111-126, 2009.

OLIVEIRA, Sara. Explorando o texto visual em sala de aula. Revista de Linguística Aplicada, vol. 46, nº 2, p. 181 -197, 2007.

PACHECO, Lílian M.B. Tempo e Narrativa In PACHECO, TRINCHÃO (Org.) Tempo, cultura, linguagem: reflexões sobre área do conhecimento do desenho e algumas implicações. Salvador: EDUFBA, 2017, pp.99-115. 
PIAGET, J.; INHELDER, B. A Psicologia da Criança. Rio de Janeiro: Bertrand Brasil, 1994.

PILLAR, Analice. Desenho e Escrita como Sistema de representação. Porto Alegre: Artes Médicas, 1996.

ROCHA, Ruth. O amigo do Rei. Editora Salamanca: $1^{\circ}$ edição, 2009.

SANTOS, Litza Pereira. Produção Acadêmica sobre Desenho na Educação Infantil. In: PACHECO, Lílian Miranda Bastos (Org.). Temas Essenciais na Educação Infantil. Salvador: EDUFBA, 2014, v.1.

SOUZA, Gabriela Barbosa. Os Contos do Povo Indígena Pataxó Hãhãhãi: Um Diálogo Intercultural. 206f. Dissertação (Mestrado Acadêmico em Educação) Universidade Estadual de Feira de Santana, Bahia, 2016.

SOUZA, G. B., PACHECO, L. M. B. \& SUZART, N. S. As Imagens Visuais e o Processo de Aprendizagem. In: Anais do IV Colóquio Internacional Educação, Cidadania e Exclusão: Didática e Avaliação. Universidade Estadual do Rio de Janeiro, 2015.

TRAVAGLIA, Luiz Carlos. A caracterização de categorias de texto: tipos, gêneros e espécies. Revista Alfa, São Paulo, v. 1, n. 51, pp. 39-79, 2007.

VIEIRA, A.; SPERB, T. O brincar simbólico e a organização narrativa da experiência de vida na criança. Revista Psicologia: Reflexão e Crítica, v. 20, n.1, p. 9-19, 2007.

VIEIRA, André; SPERB, Tânia. O brinquedo simbólico como uma narrativa. Revista Psicologia: Reflexão e Crítica, V.11, n.2 p. 1-15, 1998.

ZAMBONI, Ernesta. Representações e Linguagens no ensino de história. Revista Brasileira de História, São Paulo, v. 18, n. 36, 1998. 